\title{
A vulnerability analysis approach for the Portuguese West Coast
}

\author{
C. Coelho ${ }^{1}$, R. Silva ${ }^{2}$, F. Veloso-Gomes ${ }^{2}$ \& F. Taveira Pinto ${ }^{2}$ \\ ${ }^{l}$ Civil Engineering Autonomous Section, University of Aveiro, Portugal \\ ${ }^{2}$ Hydraulics and Water Resources Institute, Faculty of Engineering, \\ University of Porto, Portugal
}

\begin{abstract}
Coastal dynamics and erosion processes may cause serious damage, especially to people and assets in urban fronts, and they therefore merit special attention. To diminish the effects of these natural dynamics on coastal areas it is necessary to understand the various processes involved. The classification of a coast in terms of vulnerability and risk will only be possible when foresight capacity is improved, making the planning and decision processes easier. Coastal zone vulnerability to energetic environmental actions (waves, tides, winds and currents) may be considered to be biophysical systems sensitivity and morphological changes as the response. The present changes in the frequency of extreme events, the weakening of river sediments supply, the generalized sea level rise and other climatic changes, together with the advance of urban fronts towards the sea, may worsen the consequences of floods and land loss. The vulnerability analysis of coastal zones is crucial for appropriate land use, and is a complex process which involves many parameters. As a first approach an effective methodology is proposed and applied to the coastal region of the Aveiro district, south of Porto, Portugal, where the volume of available sediment is currently deficient in relation to the transport capacity, and it is predictable that the erosion situation will become further aggravated in some regions. This methodology consists of obtaining a global vulnerability index, which results from the weighting of each independently classified vulnerability parameter. This approach is complemented with a coastal line evolution estimation using numerical modelling.

Keywords: vulnerability, risk, coastal zone management, Northwest Portuguese Coast, numerical modelling.
\end{abstract}




\section{Introduction}

Energetic sea action on the coast plays a significant role in the vulnerability analysis of coastal zones. This is the main aspect to consider in the adoption and quantification of a vulnerability index. Other important factors which are not considered in this analysis are oil spills and pollutant discharges (related with navigation), diffuse pollution, seismic actions (including tsunamis), the exploitation of living resources and tourism.

For accurate classification of coastal vulnerability in coastal categorization several factors should be weighted, and are essential to understanding the related phenomena and processes. Besides extreme and short-term events there is a natural dynamic in coastal zones, which is seldom amplified or anticipated by human interventions and has the reverse effect of conflicting with human activities and occupation. As a result of dynamic processes there is a generalized coastal erosion situation with land loss that is very critical in some coastal sectors, and is of great concern especially in the medium to long term.

The risk level of urban fronts and infrastructures located in coastal zones that are highly vulnerable to sea energy actions depends on the existence of coastal defences. It is also possible to identify coastal stretches which are highly vulnerable to sea action but without risk of exposure due to the inexistence of human occupation, or without economic and environmental assets. The costs of defence are rising and there is a need to evaluate intervention effects over longer time scales, Coelho [1]. Understanding and forecasting littoral evolution tendencies, especially in occupied high risk and vulnerable regions, to help in good decision making, planning and coastal management is a challenge for contemporary society.

Vulnerability maps should qualify and quantify the littoral sensitivity to energetic sea actions, delimiting critical areas. As a first approach, vulnerability maps built based on historical and recent data may be used, together with medium to long-term shoreline evolution numerical prediction models as coastal planning and managing tools.

\section{Key issues in vulnerability evaluation}

\subsection{Vulnerability parameters}

The vulnerability analysis process done with all the vulnerability parameters is highly complex. For this reason, each vulnerability parameter considered was classified, based on individually defined criteria. Vulnerability classification ranges from 1 (very low) to 5 (very high).

In Table 1 a proposal for the classification of five vulnerability parameters based on classes defined for each of them is presented. The topographic elevation is one of the most relevant vulnerability parameters, making the distinction between low-lying coasts and those with high declivity. The distance to shoreline is another important parameter, namely the distance from an urban front or a structure to the shoreline. Naturally, the vulnerability index is lower 
further inland as the distance to the sea-land interface increases. This aspect is necessarily related to the time scale of the analysis, since the shoreline positions change with time.

The vulnerability classification as a function of the tidal range follows Gornitz et al. proposal [2]. The significant wave heights acting on a coastal region are an indicator of the characteristic wave energy and are directly related to the potential longshore transport. In this manner, a sheltered coastal region is the least vulnerable.

Coastal dynamics are well represented by the shoreline change rate. The erosion/accretion rate maintains the accumulated dynamic process over time. Historical registers of this parameter, usually related to human interventions, are very useful in trying to predict future evolutions under given scenarios, Coelho and Veloso-Gomes [3].

In Table 2 four more vulnerability parameters are presented, which are related with natural and anthropogenic characteristics of the coastal zone.

Table 1: $\quad$ Vulnerability classification (I).

\begin{tabular}{|l|c|c|c|c|c|}
\hline \multicolumn{1}{|c|}{ Vulnerability } & Very low & Low & Moderated & High & Very High \\
\cline { 2 - 6 } & 1 & 2 & 3 & 4 & 5 \\
\hline $\begin{array}{l}\text { TE - Elevation referred to } \\
\text { Chart Datum (CD) (m) }\end{array}$ & $>30$ & $\begin{array}{c}>20 \\
\leq 30\end{array}$ & $\begin{array}{c}>10 \\
\leq 20\end{array}$ & $\begin{array}{c}>5 \\
\leq 10\end{array}$ & $\leq 5$ \\
\hline DS - Distance to shore (m) & $>1000$ & $\begin{array}{c}>200 \\
\leq 1000\end{array}$ & $\begin{array}{c}>50 \\
\leq 200\end{array}$ & $\begin{array}{c}>20 \\
\leq 50\end{array}$ & $\leq 20$ \\
\hline TR -Tidal range (m) & $<1.0$ & $\begin{array}{c}\geq 1.0 \\
<2.0\end{array}$ & $\begin{array}{c}\geq 2.0 \\
\leq 4.0\end{array}$ & $\begin{array}{c}>4.0 \\
\leq 6.0\end{array}$ & $>6.0$ \\
\hline $\begin{array}{l}\text { WH - Maximum wave } \\
\text { height (m) }\end{array}$ & $<3.0$ & $\begin{array}{c}\geq 3.0 \\
<5.0\end{array}$ & $\begin{array}{c}\geq 5.0 \\
<6.0\end{array}$ & $\begin{array}{c}\geq 6.0 \\
<6.9\end{array}$ & $\geq 6.9$ \\
\hline $\begin{array}{l}\text { EA - Erosion/Accretion } \\
\text { rate (m/year) }\end{array}$ & $\begin{array}{c}>0 \\
\text { accretion }\end{array}$ & $\begin{array}{c}>-1 \\
\leq 0\end{array}$ & $\begin{array}{c}>-3 \\
\leq-1\end{array}$ & $\begin{array}{c}>-5 \\
\leq-3\end{array}$ & $\begin{array}{c}\leq-5 \\
\text { erosion }\end{array}$ \\
\hline
\end{tabular}

Table 2: $\quad$ Vulnerability classification (II).

\begin{tabular}{|c|l|l|l|l|}
\hline Vuln. & GL - Geology & $\begin{array}{l}\text { GM }- \\
\text { Geomorphology }\end{array}$ & $\begin{array}{l}\text { GC - Ground } \\
\text { Cover }\end{array}$ & $\begin{array}{l}\text { AA - Anthropogenic } \\
\text { Actions }\end{array}$ \\
\hline 1 & Magmatic rocks & Mountains & Forest & $\begin{array}{l}\text { Shoreline stabilization } \\
\text { intervention }\end{array}$ \\
\hline 2 & $\begin{array}{l}\text { Metamorphic } \\
\text { rocks }\end{array}$ & Rocky cliffs & $\begin{array}{l}\text { Ground } \\
\text { vegetation, } \\
\text { cultivated } \\
\text { ground }\end{array}$ & $\begin{array}{l}\text { Intervention without } \\
\text { sediment sources } \\
\text { reduction }\end{array}$ \\
\hline 3 & Sedimentary rocks & $\begin{array}{l}\text { Erosive cliffs, } \\
\text { Sheltered beaches }\end{array}$ & Non-covered & $\begin{array}{l}\text { Intervention with } \\
\text { sediment sources } \\
\text { reduction }\end{array}$ \\
\hline 4 & $\begin{array}{l}\text { Non-consolidated } \\
\text { coarse sediments }\end{array}$ & $\begin{array}{l}\text { Exposed beaches, } \\
\text { flats }\end{array}$ & Rural urbanized & $\begin{array}{l}\text { Without intervention } \\
\text { or sediment sources } \\
\text { reduction }\end{array}$ \\
\hline 5 & $\begin{array}{l}\text { Non-consolidated } \\
\text { fine sediments }\end{array}$ & $\begin{array}{l}\text { Dunes, river } \\
\text { mouths, estuaries }\end{array}$ & $\begin{array}{l}\text { Urbanized or } \\
\text { industrial }\end{array}$ & $\begin{array}{l}\text { Without intervention } \\
\text { but with sediment } \\
\text { sources reduction }\end{array}$ \\
\hline
\end{tabular}


Geological maps give information about the nature of rocks and sediments, and based on the behaviour and on hardness scale of their constituent minerals it is possible to make a vulnerability classification. Magmatic or eruptive rocks, for example, are very hard and therefore their vulnerability to sea action is very low. On the other extreme of classification are the small, non-consolidated sediments.

Coastal zone geomorphology is another aspect to consider, and a distinction should be made between mountainous coastal zones and beaches or dunes.

The ground cover is rarely considered in vulnerability analysis. However, different morphological behaviours can be expected depending on the type of cover: vegetation, surfacing material or bare ground.

Human interventions influence the natural behaviour of coastal dynamics and have an impact on transported littoral sediment volumes. Hydroelectric installations, dredging in navigation channels, breakwaters and groins, sand extraction, urbanization in dynamic zones and dune systems destruction can aggravate coastal erosion and increase its vulnerability.

Vulnerability classification of anthropogenic actions must also consider the potential sediment transport (wave generated) and the available sediment volume, after reduction from the weakened sediment supply to the coastal environment. The probability of erosion is also determined by the existence of coastal defences and their effectiveness, and it is expected to be lower in regions where these interventions have already been made. The defence interventions classified as shoreline stabilization include longitudinal and transversal structures, such as detached breakwaters, longitudinal defences, groins and groin fields, as well as port breakwaters. Other kinds of interventions are artificial beach nourishment and palisades for sand retention. Note that the classification of an area with an existing defence intervention assumes its effectiveness during the whole analysis period, performed by periodic monitoring and maintenance operations. If these are not performed a review of the vulnerability classification should be made.

\subsection{Vulnerability parameter weighting}

The referred parameters are relevant for coastal vulnerability evaluation with respect to energetic sea actions, however their relative importance is, of course, not the same, and so they should have different weights in a global vulnerability classification. Since their importance is variable from region to region the weighting criteria are difficult to establish. In this study three different weighting criteria were established, as shown in Table 3.

One of the weighting criteria, called "Weighting 1", is the arithmetic mean and corresponds to equal weighting for all of the considered parameters.

The second criterion, "Weighting 2", reduces ground cover and tidal range importance. This alternative follows the fact that the ground cover is usually not considered in this kind of classification, and that the approach to considering tidal range is not consensual, furthermore, tidal effect should be uniform in all regions of a coastal zone, Coelho et al. [4]. Under this criterion, geology and distance to shoreline are given a higher weight, since they are key determiners of 
vulnerability classification. In fact, rocky regions or those distant from shore are necessarily low in vulnerability.

Table 3: Vulnerability parameters weighting coefficients.

\begin{tabular}{|l|c|c|c|}
\hline Vulnerability Parameters & Weighting 1 & Weighting 2 & Weighting 3 \\
\hline TE - Elevation referred to CD (m) & 1 & 1 & 7 \\
\hline DS - Distance to shore (m) & 1 & 2 & 8 \\
\hline TR - Tidal range (m) & 1 & 0.5 & 2 \\
\hline WH - Maximum wave height (m) & 1 & 1 & 5 \\
\hline EA - Erosion/Accretion rate (m/year) & 1 & 1 & 3 \\
\hline GL - Geology & 1 & 2 & 9 \\
\hline GM - Geomorphology & 1 & 1 & 4 \\
\hline GC - Ground cover & 1 & 0.5 & 1 \\
\hline AA - Anthropogenic actions Total & 1 & 1 & 6 \\
\hline \multicolumn{2}{|r|}{} & 10 & 45 \\
\hline
\end{tabular}

The third proposed criterion, "Weighting 3", corresponds to a scaling of all parameter weights, from 1 to 9 . The increasing order of parameter importance was: ground cover, tidal range, erosion/accretion rate, geomorphology, maximum wave height, anthropogenic actions, topographic elevation, distance to shoreline and geology. Geology was considered to be the most important parameter because a rocky coastal zone has a very low vulnerability. Places which are distant from shoreline are naturally protected from sea actions and so have low vulnerability. Elevated points or artificially effective protected zones also reduce vulnerability. The energetic wave potential was considered to be an intermediate parameter in weighting, while geomorphology and coastline evolution trends (erosion/accretion rate) represent parameters with lower importance for vulnerability classification. As in "Weighting 2" criterion, ground cover and tidal range are considered to be less important vulnerability parameters.

\section{Vulnerability analysis of Aveiro Portuguese coastal sector}

\subsection{Introduction}

The proposed methodology is currently applied to several sectors of the Portuguese west coast. Fifty western Portugal coastal stretches have already been classified because it is thought that the methodology calibration should be accomplished by its application to a large number of case studies, Coelho et al. [4]. In this article the vulnerability analysis methodology presented is applied to the coastal sector of Aveiro district.

\subsection{Vulnerability matrix}

It is important to note the high degree of subjectivity connected with the vulnerability classification. Data acquisition, data collection and knowledge of coastal dynamics are the best tools for limiting any inherent subjectivity in 
classification. Extended data bases and data access simplification will allow for a better evaluation of erosion/accretion rates, wave climate, ground cover mapping and behaviour of coastal dynamics after defence work construction, and will consequently improve the evaluation of respective vulnerability parameters.

\section{Coastal Municipalities of Aveiro District.}

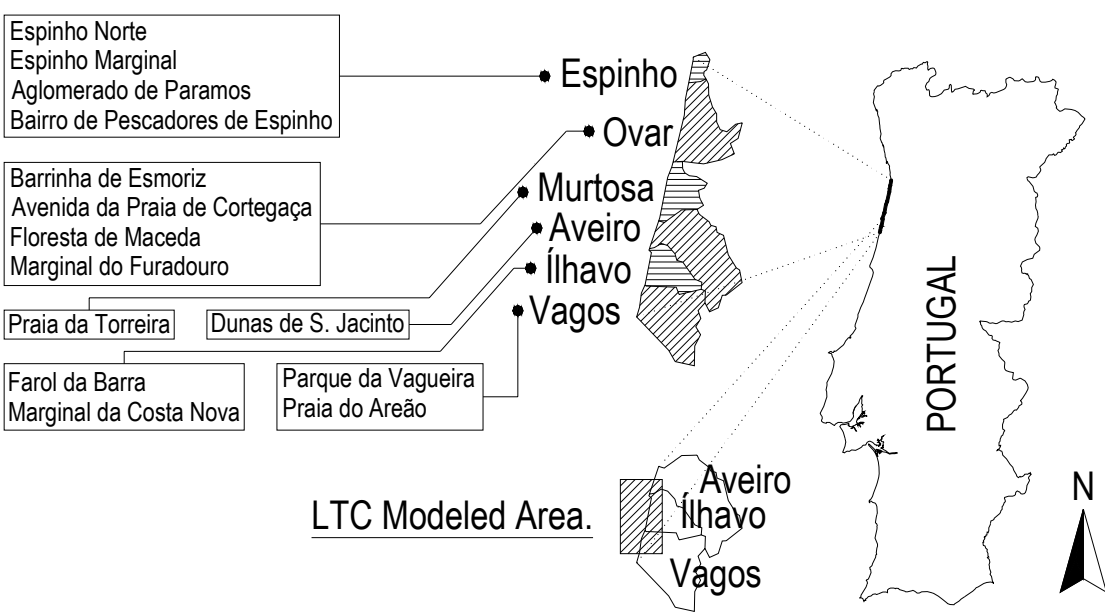

Figure 1: Northwest Portugal coastal stretch under vulnerability analysis.

Three criteria were defined for vulnerability parameter weighting for the purpose of making a sensitivity analysis of the weighting procedure. The classification is based on the present characteristics of the area, so the possibility of conditions changing over time may limit the evaluation horizon.

The vulnerability matrix is presented in Table 4, where a possible classification given to each of the indicated parameters in the study area is shown.

For the tidal range parameter a classification of 3 is given, which is valid for almost the entire northwest coast of Portugal.

The wave climate of the Portuguese northwest coast may be considered as highly energetic, and this is represented in the analysis by classifying the corresponding vulnerability parameter with a 5. Exceptions to this classification are places where the wave propagation to the shore is interrupted by obstacles (either natural ones such as rocky zones or bays, or artificial, such as port breakwaters) protecting the shore. From the classified locations, only Farol da Barra in Aveiro district was given a lower vulnerability classification for this parameter.

The erosion/accretion rates along the shore are highly variable. This is essentially related to a smaller up-drift river sediment supply, shoreline 
orientation and its relation with wave climate and potential longshore transport. In spite of the general transported sediment deficit along the Portuguese west coast there are some places where accretion occurs up-drift from coastal defences or natural capes, resulting in a stable shoreline or advance towards the sea. Sometimes the estimated erosion/accretion rates are not clear and may be related to particular situations occurring for a short period of time. In fact, this parameter is one of the most difficult to evaluate. To achieve such an evaluation it is crucial to use good critical thinking and have extensive knowledge of the region.

Table 4: Vulnerability matrix for the Aveiro coastal sector.

\begin{tabular}{|l|c|c|c|c|c|c|c|c|c|}
\hline \multirow{2}{*}{ Local } & \multicolumn{8}{|c|}{ Vulnerability Parameters } \\
\cline { 2 - 12 } & TE & DS & $\begin{array}{c}\text { T } \\
\text { R }\end{array}$ & WH & EA & GL & $\begin{array}{c}\text { G } \\
\text { M }\end{array}$ & GC & AA \\
\hline Espinho Norte & 4 & 3 & 3 & 5 & 2 & 5 & 4 & 2 & 1 \\
\hline Espinho Marginal & 5 & 4 & 3 & 5 & 2 & 5 & 4 & 5 & 2 \\
\hline Aglomerado de Paramos & 5 & 4 & 3 & 5 & 4 & 5 & 4 & 4 & 2 \\
\hline $\begin{array}{l}\text { Bairro de Pescadores } \\
\text { Espinho }\end{array}$ & 5 & 4 & 3 & 5 & 4 & 5 & 4 & 5 & 2 \\
\hline Barrinha de Esmoriz & 5 & 3 & 3 & 5 & 4 & 5 & 4 & 3 & 2 \\
\hline Av. da praia de Cortegaça & 5 & 5 & 3 & 5 & 5 & 5 & 4 & 5 & 2 \\
\hline Floresta de Maceda & 5 & 5 & 3 & 5 & 5 & 5 & 4 & 1 & 5 \\
\hline Marginal do Furadouro & 5 & 5 & 3 & 5 & 4 & 5 & 4 & 5 & 2 \\
\hline Praia da Torreira & 5 & 5 & 3 & 5 & 3 & 5 & 4 & 5 & 2 \\
\hline Dunas de S. Jacinto & 5 & 5 & 3 & 5 & 1 & 5 & 5 & 3 & 4 \\
\hline Farol da Barra & 5 & 5 & 3 & 3 & 2 & 5 & 5 & 5 & 2 \\
\hline Marginal da Costa Nova & 5 & 5 & 3 & 5 & 4 & 5 & 4 & 5 & 2 \\
\hline Parque da Vagueira & 5 & 4 & 3 & 5 & 5 & 5 & 5 & 4 & 5 \\
\hline Praia do Areão & 5 & 5 & 3 & 5 & 4 & 5 & 4 & 3 & 2 \\
\hline
\end{tabular}

The analysed locations correspond mainly to typical sandy beaches, representing very vulnerable geological sites and geomorphologic index values of 4 . The ground cover and anthropogenic actions are also highly variable. The anthropogenic actions parameter is also difficult to classify, with experience and good knowledge of the location being important once again. There are several situations where the existence of defences to shoreline stabilization have been accompanied by shoreline retreat due to up-drift dredging or sediment retention in breakwaters, which justifies a high vulnerability classification. The reverse may also occur in places where there are no interventions but there is shoreline stability.

A vulnerability classification of the Aveiro coastal sector is given in Table 5, where VHV means very high vulnerability (VHV $\geq 4.5)$, HV means high vulnerability $(3.5 \leq \mathrm{HV}<4.5)$ and IV intermediate vulnerability $(2.5 \leq \mathrm{IV}<3.5)$.

From an analysis of Table 5 it is seen that the results are generally high, showing the sensitivity of the coastal area where the analysed sites are inserted. These sites are very close to shoreline and low-lying areas, which directly results in high classifications for the respective parameters. 
Table 5: Vulnerability classification of Aveiro coastal sector.

\begin{tabular}{|l|c|c|c|c|c|c|}
\hline \multirow{2}{*}{ Local } & \multicolumn{5}{|c|}{ Vulnerability Classification } \\
\cline { 2 - 8 } & \multicolumn{3}{|c|}{ Weighting 1 } & \multicolumn{2}{c|}{ Weighting 2 } & \multicolumn{2}{c|}{ Weighting 3 } \\
\hline Espinho Norte & 3.2 & IV & 3.5 & IV & 3.5 & HV \\
\hline Espinho Marginal & 3.9 & HV & 4.0 & HV & 4.0 & HV \\
\hline Aglomerado de Paramos & 4.0 & HV & 4.2 & HV & 4.2 & HV \\
\hline Bairro de Pescadores Espinho & 4.1 & HV & 4.2 & HV & 4.2 & HV \\
\hline Barrinha de Esmoriz & 3.8 & HV & 3.9 & HV & 4.0 & HV \\
\hline Av. da praia de Cortegaça & 4.3 & HV & 4.5 & VHV & 4.4 & HV \\
\hline Floresta de Maceda & 4.2 & HV & 4.6 & VHV & 4.7 & VHV \\
\hline Marginal do Furadouro & 4.2 & HV & 4.4 & HV & 4.4 & HV \\
\hline Praia da Torreira & 4.1 & HV & 4.3 & HV & 4.3 & HV \\
\hline Dunas de S. Jacinto & 4.0 & HV & 4.3 & HV & 4.5 & HV \\
\hline Farol da Barra & 3.9 & HV & 4.1 & HV & 4.1 & HV \\
\hline Marginal da Costa Nova & 4.2 & HV & 4.4 & HV & 4.4 & HV \\
\hline Parque da Vagueira & 4.6 & VHV & 4.7 & VHV & 4.7 & VHV \\
\hline Praia do Areão & 4.0 & HV & 4.3 & HV & 4.3 & HV \\
\hline
\end{tabular}

\subsection{Results analysis}

From analysis of Table 5 it follows that by using equal weighting for all the parameters the global vulnerability is between 3.2 and 4.6. The other two criteria globally increase the vulnerability index, ranging from 3.5 to 4.7 in both cases. The "Weighting 2" criterion increases the vulnerability obtained from "Weighting 1" criterion in 4.8\%, while "Weighting 3" gives an increase of 5.4\%. However, a change in weighting coefficients is not as important for results as parameter classification is, especially due to the difficulty of making an objective analysis. This way, a change in a value in parameter classification in "Weighting 1 " represents an $11.1 \%(1 / 9)$ change in overall vulnerability. This importance is higher for "Weighting 2" where a change in geology and distance to shoreline parameters in a value results in a $20 \%$ change $(2 / 10)$. Nevertheless, these parameters are easier to objectively classify, thereby reducing error probability. For "Weighting 3" criterion, changes in most relevant parameters may result in different changes with a maximum of 20\% (9/45) for geology. This analysis shows that accurate parameter classifications are more important than their weighting.

The "Weighting 1" criterion classifies one location with very high vulnerability twelve with high vulnerability, and only one of the analysed sites has intermediate vulnerability. According to this criterion the Aquatic Park of Vagueira is the most vulnerable site. This is essentially due to the high vulnerability to anthropogenic actions and ground cover.

When the weighting criterion changes to "Weighting 2", two locations change from high to very high vulnerability: Cortegaça's beach avenue and Maceda Forest. The highest change $(8.9 \%)$ occurs in Maceda Forest, which is due to the reduced importance of ground cover since this site has high values for the most important parameters according to this criterion. Cortegaça also rises in the classification (3.8\%) because it has maximum geological vulnerability. 
Using the "Weighting 3 " criterion results in two changes when compared to "Weighting 2". Espinho Norte classification increases from intermediate vulnerability to high vulnerability and Cortegaça decreases from very high vulnerability to high vulnerability. The changes relative to "Weighting 1" show only two rises: Espinho Norte (9.0\%) and the highest for Maceda Forest (12.1\%).

\subsection{Vulnerability maps}

With the aim of developing a tool that will help the decision-making process with quick and intuitive vulnerability visualization for coastal categorization, vulnerability maps are being built. Vulnerability maps should qualify and quantify the littoral sensitivity to energetic sea actions, delimiting critical areas. In this paper the cartographic representation under development is presented for the Aveiro district.
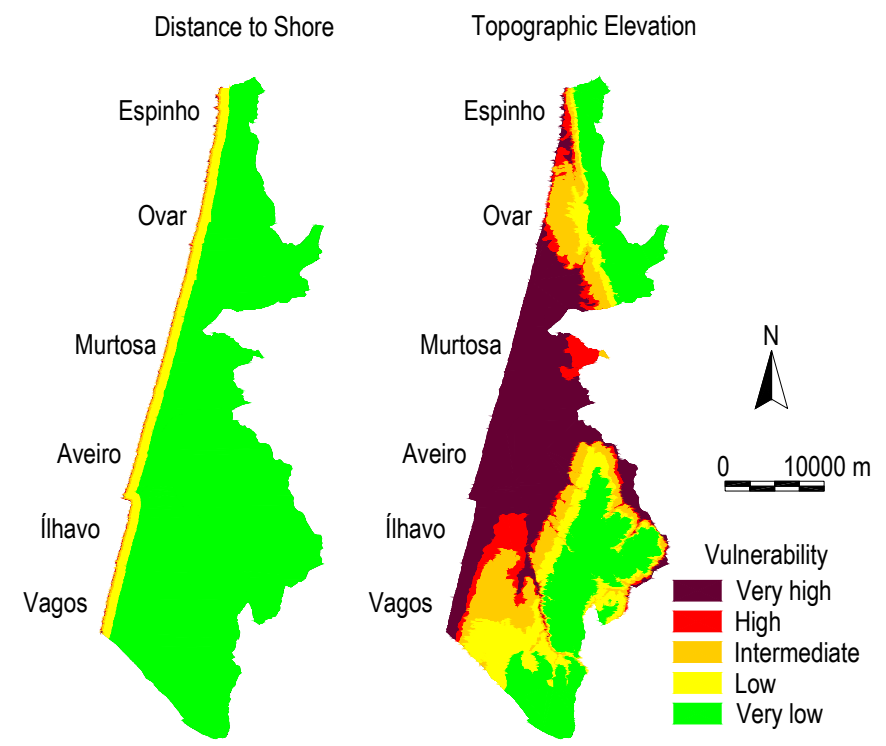

Figure 2: Cartographic representation of two vulnerability parameters for Aveiro district.

The vulnerability parameters seen in Figure 2 are distance to shoreline and topographic elevations, and classification distribution. From an analysis it is immediately clear that the highest classifications related with the distance to shoreline occur in a coastal strip extending alongshore. The second represented parameter shows the low-lying Aveiro Lagoon with high or very high vulnerability. Both cartographic representations were based on military maps from Instituto Geográfico do Exército.

The mapping of the parameters related to tides and waves is still under development. For these parameters, the inner regions will have the same values as the littoral. Similar assumptions are made for representing the 
erosion/accretion rates and anthropogenic actions. Vulnerability representations of geological and geomorphologic parameter classifications are based on Portuguese Geological Maps. Ground cover classification will be based on ground occupation maps from Instituto Geográfico Português (August 1990).

The combination of all parameters in a single map must be done with care, and the analysis presented in Table 5 will be used to calibrate the methodology. All the sites presented in this study are located near the sea. The weighting of the distance-to-shoreline parameter should increase for higher distances. The objective of combining information in a single vulnerability map is to create an effective tool for high vulnerability coastal zone identification and delimiting.

\subsection{Shoreline evolution numerical modelling}

The vulnerability analysis should be complemented with a medium to long term shoreline evolution prediction. Numerical models may be used to predict the future shoreline position. However, the results are purely advisory and should be used with care and in respect to current knowledge. A medium to long term numerical shoreline evolution model in its final development phase, the LTC (Long Term Configuration), Coelho [1], was applied to the Aveiro coastal sector (the modelled area is indicated in Figure 1).

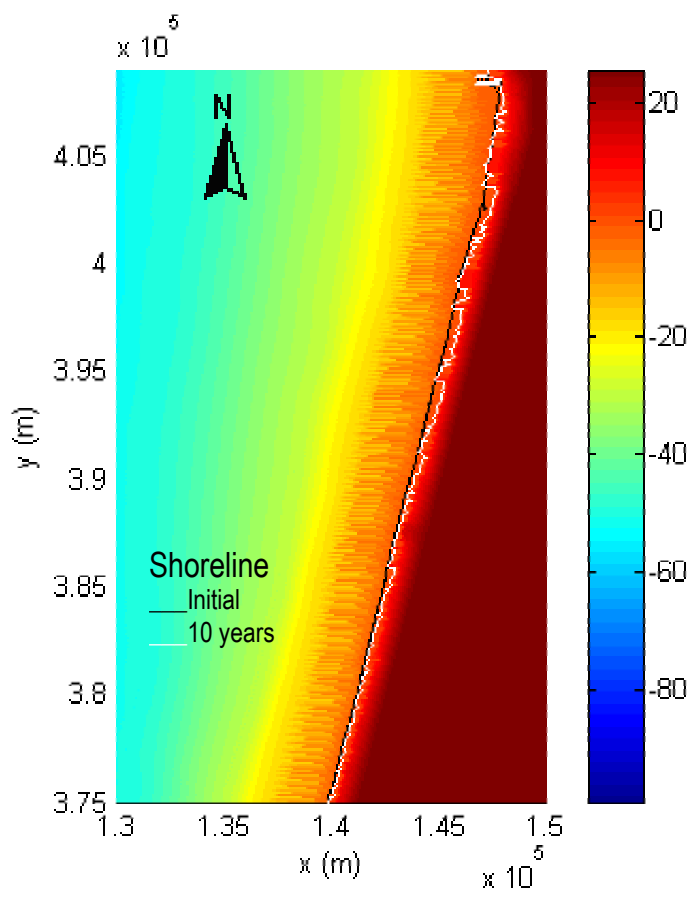

Figure 3: LTC results for the Aveiro coastal area for ten years.

The model was used for a 10-year period. It has been forced with a typical annual wave climate for Aveiro coastal region, Coelho [1]. The bathymetric 
support was a nautical chart from Instituto Hidrográfico (ed. 2000) and the topographic support was an aerial survey from Instituto Geográfico Português (1996).

In Figure 3 the model bathymetric results are presented: the 1996 shoreline and the shoreline and bathymetry changes in ten years time. The erosion tendency accompanied by shoreline retreat in the highly vulnerable zone of Aveiro Lagoon may be seen.

\section{Conclusions}

Careful application of vulnerability classification criteria together with improved shoreline evolution predictions can help decision makers in the planning and management of coastal zones, contributing to a better quality of life in those regions, Veloso-Gomes and Taveira Pinto [5]. A protection strategy should include the delimitation of vulnerable zones for extreme events and evolution of coastal dynamics, areas with building restrictions, natural buffer zones, protection and rehabilitation of dune systems and other ecosystems, coastal defence intervention planning and implementation, flood control interventions, definition of stability safety codes for licensing, planning and construction of buildings and infra-structures and the possibility of their future relocation, retreated positioning of infra-structures to be used in emergency circumstances (hospitals, schools, police, ...) and establishment of emergency plans, Coelho and Veloso-Gomes [3].

In this article the vulnerability analysis methodology presented was applied to the coastal sector of Aveiro district. Nine vulnerability parameters were considered and classified, based on individually defined criteria. Three criteria were defined for weighting the vulnerability parameters for the purpose of making a sensitivity analysis of the weighting procedure. This analysis showed that an accurate parameter classification is more important than specific weighting.

In the study area the Vagueira Aquatic Park was found to be the most vulnerable location, followed by Cortegaça's beach avenue and Maceda Forest. Espinho Norte was also considered to be highly vulnerable.

Aiming for the development of a tool with quick and intuitive vulnerability visualization for coastal categorization, vulnerability maps are being built. In this paper the cartographic representation under development was presented for two vulnerability parameters in the Aveiro district.

The vulnerability analysis was complemented with a medium to long term shoreline evolution prediction using numerical modelling. The highly vulnerable zone of Aveiro Lagoon showed an erosion tendency accompanied by a general shoreline retreat.

\section{References}

[1] Coelho, C., "Riscos de Exposição de Frentes Urbanas Para Diferentes Intervenções de Defesa Costeira", Ph.D Thesis, University of Aveiro, 404 pp, 2005. 
[2] Gornitz, V.M., Beaty, T.W., Daniels, R.C., A Coastal Hazards Data Base for the U.S. West Coast, Environmental Sciences Division Publication n. ${ }^{\circ}$ 4590, ORNL/CDIAC-81, NDP 043C, 78 p, 1997.

[3] Coelho, C., Veloso-Gomes, F., "Classificação de Vulnerabilidades e Riscos como Contributos no Planeamento das Zonas Costeiras", III Congresso sobre Planeamento e Gestão das Zonas Costeiras dos Países de Expressão Portuguesa, Moçambique, 15 p, 2005.

[4] Carlos Coelho, Márcia Cabarrão D’Albuquerque, Fernando VelosoGomes, "Aplicação de uma Classificação de Vulnerabilidades às Zonas Costeiras do Noroeste Português"; $8^{\circ}$ Congresso Nacional da Água, Portugal, 2006 (accepted).

[5] Veloso-Gomes, F., Taveira-Pinto, F. A Opção "Protecção" para a Costa Oeste Portuguesa, Colectânea de Ideias Sobre a Zona Costeira de Portugal, Associação Eurocoast Portugal, pp. 163-190, 1997. 